\title{
Response of internal solitary waves to tropical storm Washi in the northwestern South China Sea
}

\author{
Z. H. Xu ${ }^{1,2}$, B. S. Yin ${ }^{1,2}$, and Y. J. Hou ${ }^{1,2}$ \\ ${ }^{1}$ Institute of Oceanology, Chinese Academy of Sciences, Qingdao 266071, China \\ ${ }^{2}$ Key Laboratory of Ocean Circulation and Waves (KLOCAW), Chinese Academy of Sciences, Qingdao 266071, China
}

Received: 4 September 2011 - Revised: 28 October 2011 - Accepted: 16 November 2011 - Published: 29 November 2011

\begin{abstract}
Based on in-situ time series data from an array of temperature sensors and an acoustic Doppler current profiler on the continental shelf of the northwestern South China Sea, a sequence of internal solitary waves (ISWs) were observed during the passage of tropical storm Washi in the summer of 2005, which provided a unique opportunity to investigate the ISW response to the tropical cyclone. The passing tropical storm is found to play an important role in affecting the stratification structure of the water column, and consequently leading to significant variability in the propagating features of the ISWs, such as the polarity reversal and amplitude variations of the waves. The response of the ISWs to Washi can be divided into two stages, direct forcing by the strong wind (during the arrival of Washi) and remote forcing via the nearinertial internal waves induced by the tropical storm (after the passage of Washi). The field observations as well as a theoretical analysis suggest that the variations of the ISWs closely coincide with the changing stratification structure and shear currents in accompanied by the typhoon wind and nearinertial waves. This study presents the first observations and analysis of the ISW response to the tropical cyclone in the South China Sea.
\end{abstract}

Keywords. Meteorology and atmospheric dynamics (Ocean-atmosphere interactions; Waves and tides)

\section{Introduction}

Internal solitary waves (ISWs) are commonly observed all over the world ocean, especially on the continental shelves (Liu et al., 1998; Ramp et al., 2004), in the marginal seas (Klymak et al., 2006) and straits (Vlasenko and Hutter, 2002). They usually arise from the steepening of the strong

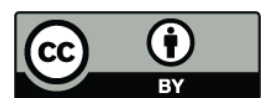

Correspondence to: $\mathrm{Z}$. $\mathrm{H} . \mathrm{Xu}$

(xuzhenhua@qdio.ac.cn) internal tides (Lien et al., 2005; Mihanović et al., 2006; Xu et al., 2011). The large amplitude ISWs accompanied by strong shear currents can cause serious hazards to the platform structures and drilling operations in the oceans. The ISWs in the South China Sea (SCS) are among the strongest of the world with the amplitude reaching $170 \mathrm{~m}$ or more (Liu et al., 2004; Klymak et al., 2006), which is much larger than the largest surface waves with the height of $32.3 \mathrm{~m}$ ever recorded among the world seas (Liu et al., 2008). Hence, there is increasing interest in the study of ISWs in this area, and most previous research focuses on the generation mechanisms and propagation characteristics of the solitons. It has been accepted that the ISWs in the northeastern SCS mainly arise from the nonlinear steepening of the baroclinic tides or lee-waves generated by the tide-topography interactions at the Luzon Strait, whereas in the northwestern SCS, the locally generated ISWs also make important contributions to the local internal wave field (Xu et al., 2010b).

Recently, the connection between the ISWs and other oceanic processes has attracted the attention of many researchers. Liu et al. (1998) firstly suggested that the Kuroshio significantly affected the formations of both elevation and depression internal waves in different environment conditions. Based on the analysis from the linear wave theories, Yuan et al. (2006) also suggested that the instability of the Kuroshio west ring could produce westward propagating solitons. Then Du et al. (2008) further demonstrated that the Kuroshio intrusion to Luson Strait or South China Sea increased the occurrence of generating internal mixing and groups of ISWs, using remote sensing images and numerical models. In addition, The monsoon wind and heat flux are also suggested to modify the environment conditions and make the occurrence of the ISWs with seasonal variability (Zheng et al., 2007).

However, while the intense atmosphere phenomenon such as tropical storms or typhoons are also important to dramatically modify the ocean environment, their influences on the 


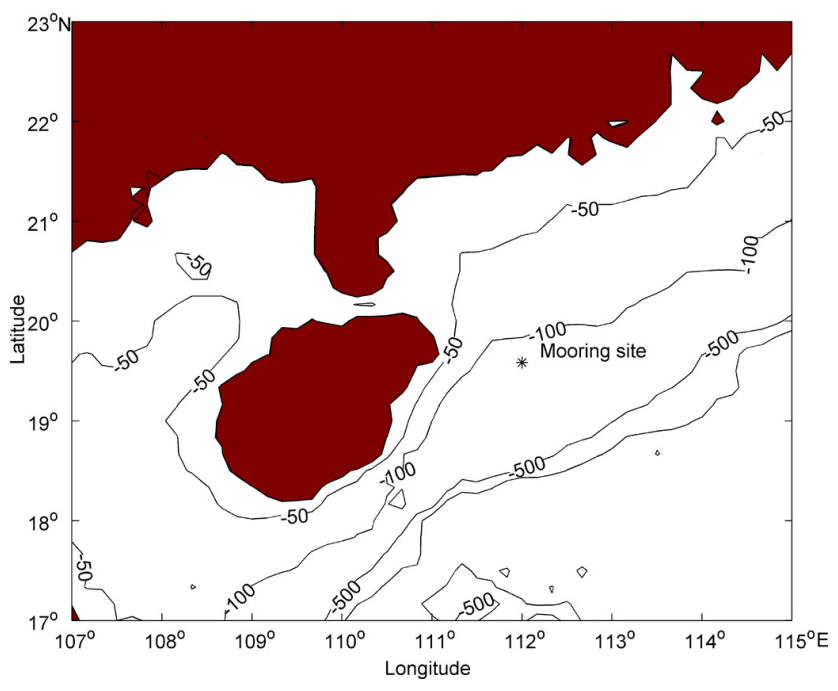

Fig. 1. Map of the study area. Contours mark isobaths in meters. Symbol * indicates the mooring position.

ISWs in the SCS remain unclear and have not been investigated yet. The SCS is a semi-closed marginal sea extending from the west Pacific to the China shelf and frequently experiences strong tropical cyclones originating from the Pacific. The strong tropical cyclones, as extremely intense meteorological forcing, can not only directly induce disastrous consequences to the community, but also result in significant response in the ocean. On the ocean surface, the tropical storm can produce strong storm surges and wind waves (Liu et al., 2008). Additionally, the typhoon can also lead to primary changes in the ocean interior. For example, it has been found that the strong vertical mixing and horizontal pressure gradients caused by the typhoon wind can cause obvious variations of the stratification structure and lead to the formation of near-inertial internal waves in the ocean interior (Chu et al., 2000).

Furthermore, it is with no doubt that the features of the ISWs will vary according to the changing oceanic environment conditions in response to the tropical storms. But due to the shortage of high resolution data set obtained during the passage of tropical cyclones, up to now, few studies have addressed the effect of typhoons or hurricanes on the highfrequency ISWs in the literature. Bogucki et al. (2005) found that the ISW suddenly reversed its polarity from wave of depression to wave of elevation during the passage of the tropical storm using the field measurements over the Middle Atlantic Bight. Based on the ocean buoy data and remote sensing image, Nam et al. (2007) further suggested that the ISWs observed across the east coast of Korea were generated by near-inertial waves in response to the typhoon wind. It should be noted that none of the previous studies have been able to give a detailed examination of the ISW response spanning the pre-typhoon to the post-typhoon period.
We conducted the Wenchang Internal Wave Experiment (WIWEX) on the continental shelf of the nothwestern SCS in 2005. Fortunately, during our measurement, a tropical storm passed over our mooring site, and high-resolution data sets spaning the arrival to the left of the typhoon were acquired, enabling us, for the first time, to examine the effects of the typhoon on the ISWs in the SCS. In the present paper, we aim to present the observations of the response of the ISWs to the tropical storm Washi, and give a preliminary theoretical analysis on the basis of a two-layer internal wave model. The paper is organized as following: Sect. 2 describes the data and methods used in this work, the background conditions are presented in Sect. 3, and Sect. 4 describes the observations of the ISWs, then the discussion and conclusion are presented in Sects. 5 and 6, respectively.

\section{Data and methods}

In this study, we use the temperature and velocity observations from 28 July to 2 August at the mooring site $\left(112^{\circ} \mathrm{E}\right.$, $19^{\circ} 35^{\prime} \mathrm{N}$ ) on the northwestern shelf of the SCS (Fig. 1). The water depth at the station is $117 \mathrm{~m}$. A $190 \mathrm{kHz}$ down-looking ADCP was positioned at a depth of $8 \mathrm{~m}$. The depth of the available current data measured by ADCP ranged from 10 to $114 \mathrm{~m}$, with a vertical interval of $2 \mathrm{~m}$. Current measurements were recorded with a precision of $1 \times 10^{-4} \mathrm{~m} \mathrm{~s}^{-1}$ at a time interval of $10 \mathrm{~min}$. The temperature sensor information with a precision of $0.01{ }^{\circ} \mathrm{C}$ and a time interval of $1 \mathrm{~min}$ was collected at 23 layers. Most of the temperature sensors were placed between 4 and $40 \mathrm{~m}$ below the sea surface with a vertical separation of less than $4 \mathrm{~m}$, whereas the bottom two sensors were located at depths of 50 and $75 \mathrm{~m}$ (Xu et al., 2010a). The salinity data from the Generalized Digital Environmental Model (GDEM) and the observed temperature profile are used to calculate the density and buoyancy frequency.

\section{Background}

Tropical storm Washi originated as a tropical cyclone from the southwest of Dongsha Island on 28 July 2005, moved towards northwest by west and intensified into a tropical storm on 29 July. The response of the ocean to the storm can be divided into two stages. Stage 1 occurred from 29 to 30 July when Washi directly affected the water column at the site during its approach and passage. On 30 July, the tropical storm was in the closest distance of the site and resulted in the most dramatic effects on the water column. Afterwards, stage 2 started after the passage of Washi when the nearinertial oscillations dominated, which was termed as "relaxation stage". In this study, all variables are examined in a 6 day period surrounding the arrival and departure of Washi (28 July-2 August). 


\subsection{Stratification structure}

The tropical storm Washi plays an important role in affecting the stratification structure of the water column (Fig. 2). The temperature data are low-passed with a cutoff of $12 \mathrm{~h}$, and the near-inertial band $(28-38 \mathrm{~h})$ and the diurnal band $(20-$ $28 \mathrm{~h}$ ) internal wave signals are also extracted from the $27^{\circ} \mathrm{C}$ isotherm profile. In this study, the seasonal thermocline is classified when the vertical temperature gradient is larger than $0.2^{\circ} \mathrm{C} \mathrm{m}^{-1}$. In general, prior to the arrival of Washi, the mixed layer depth was about $20 \mathrm{~m}$, and the seasonal thermocline was around $20-40 \mathrm{~m}$ depth. As Washi passed, the mixed layer deepened to $30 \mathrm{~m}$ or deeper, and the thermocline was also depressed between 35-60 m depth. Moreover, both the diurnal internal tides and near-inertial internal waves display interesting features during this period, which significantly affect the specific depth of the thermocline, but there are also some remarkable differences between them. The strong diurnal internal tides appeared during the whole period, whereas the near-inertial motions became dominated during and after the typhoon. Therefore, before the arrival of Washi, the variations of the seasonal thermocline were mainly attributed to the internal tides with the amplitude as large as $15 \mathrm{~m}$. Accordingly, the thermocline was located around $20 \mathrm{~m}$ during the passage of the shoulders or peaks of the internal tides, while the thermocline was depressed by the internal tides to $35 \mathrm{~m}$ or deeper when the troughs of the waves passed the mooring site (Fig. 2).

In contrast, after the passage of Washi, the near-inertial motions begin to dominate the internal wave field, though the diurnal internal tides are still present. As a result, besides for the deepening of the thermocline in response to the strong mixing caused by the typhoon wind, the specific depth and structure of the thermocline also exhibit a varying pattern at the near-inertial period owning to the near-inertial internal waves (Fig. 2a). During the passage of the troughs of the near-inertial internal waves, the mixed layer was at $40-60 \mathrm{~m}$ depth, while at the shoulders or peaks of the waves, the mixed layer was elevated to the 30-35 m depth. Generally, the upper layer depth during and after Washi is deeper than that before the tropical storm, which can significantly affect the polarities of the ISWs to be discussed in the next section.

\subsection{Baroclinic currents}

The east velocity was much stronger than the north component, hence in this section, we will use the east component to represent the baroclinic velocity structure. Figure $2 \mathrm{c}$ shows that the baroclinic currents dominate over the barotropic currents during the whole period, but there are also varying features of the baroclinic currents under the effect of the tropical storm. Before 29 July, the interface of the shear currents was situated at $20-40 \mathrm{~m}$ and the upper-layer and lowerlayer currents are comparable in amplitude on the order of $0.1 \mathrm{~m} \mathrm{~s}^{-1}$, but from 30 July when the tropic storm was in
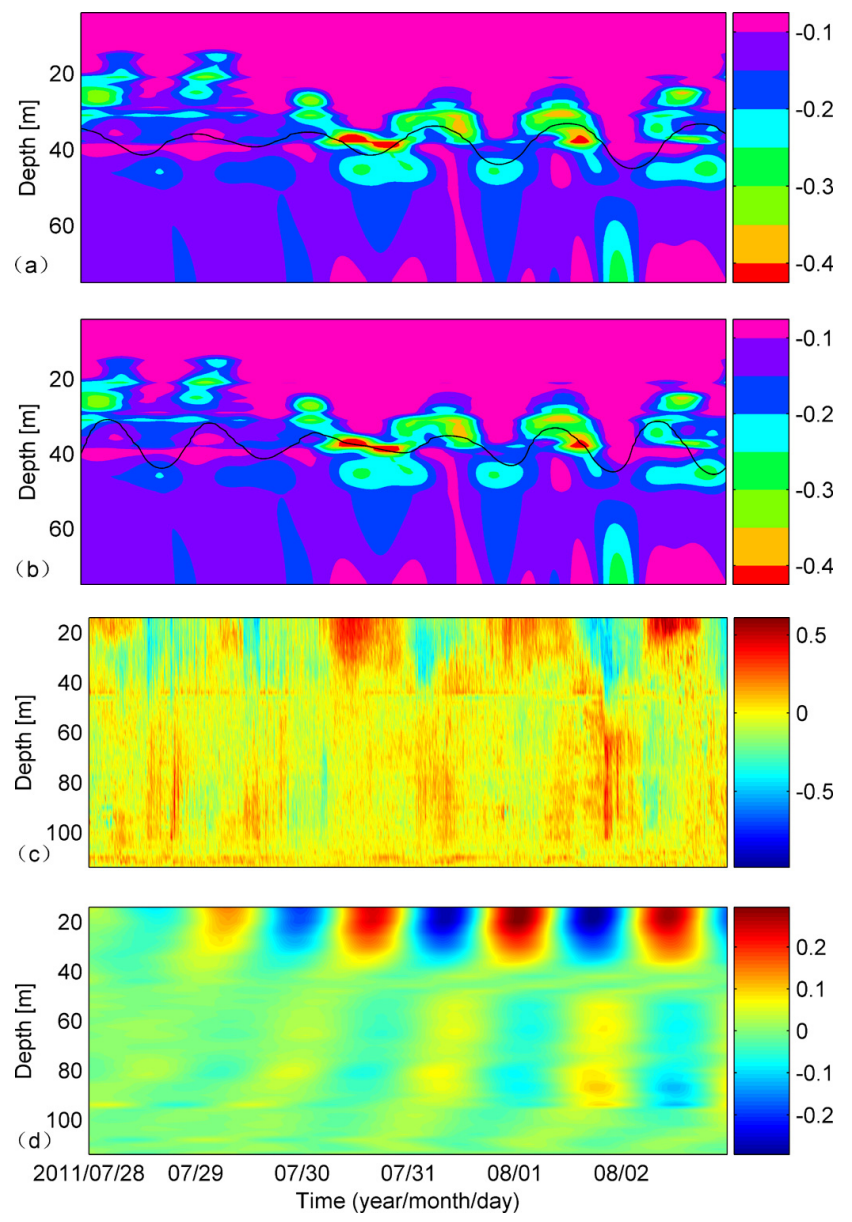

Fig. 2. Contours of the temperature gradient from 28 July to 2 August 2005, (a) near-inertial band and (b) diurnal band filtered $27^{\circ} \mathrm{C}$ isotherm depths are also noted in black line, colorbar units are ${ }^{\circ} \mathrm{C} \mathrm{m}^{-1}$. Contours of the (c) raw east baroclinic velocity and (d) band-passed east velocity with a band limit of 30-38 h from 28 July to 2 August 2005, colorbar units are $\mathrm{m} \mathrm{s}^{-1}$.

the closest distance of the site, the shear interface deepened to roughly $35-60 \mathrm{~m}$ depth and the upper-layer currents increased up to $0.4 \mathrm{~m} \mathrm{~s}^{-1}$ while the lower-layer currents remained unchanged from those before the tropical storm. In order to examine the oceanic response to Washi, we filtered the currents at a band of 30-38 h to extract the near-inertial signals. From Fig. 2d, one can see that the near-inertial internal waves are visible from 29 July in the velocity structure and on 30 July the upper-layer inertial currents reach the maximum amplitude of $0.3 \mathrm{~m} \mathrm{~s}^{-1}$ and last for more than 4 days, consistent with the variations of the raw currents shown in Fig. 2c. Therefore, the near-inertial internal waves appeared to mainly account for the increase of the shear currents and the deepening of the upper mixed layer during the passage of the tropical storm, consistent with the description based on the temperature data. In the discussion section, we will show that besides for the thermocline variations, the 

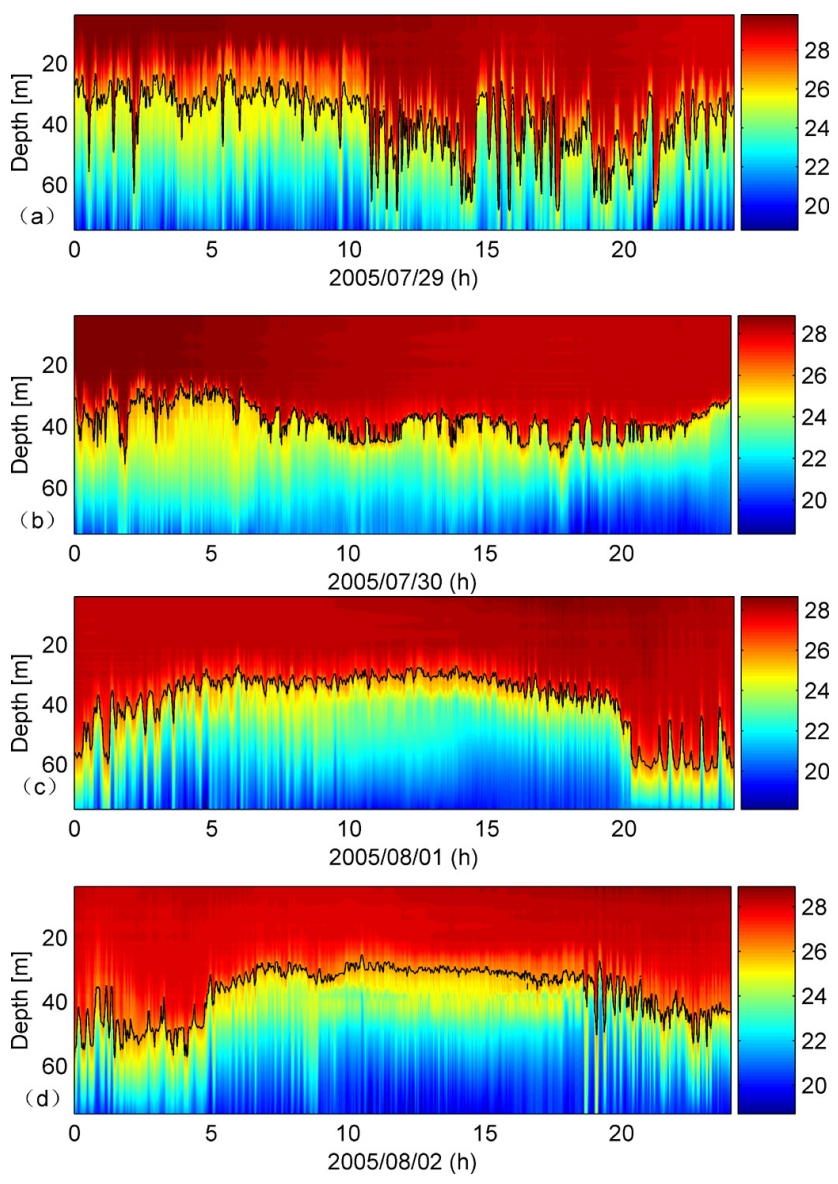

Fig. 3. Time series of isotherm depths from the temperature data on (a) 29 July, (b) 30 July, (c) 1 August and (d) 2 August 2005. The isotherm of $27^{\circ} \mathrm{C}$ is noted.

increase of the shear currents is also important in affecting the characteristics of the ISWs.

\section{Observations of the ISWs}

As described in the former section, the tropical storm Washi begins to affect the environment conditions of the mooring site from 12:00 on 29 July, but results in the strongest response in the water column from 06:00 on 30 July. Interestingly, the ISWs are also found to display distinctly different features during these two consecutive days (Fig. 3), indicating that the tropic storm probably impacts the characteristics of the waves. On 29 July, the solitons are strong with the amplitude as large as $40 \mathrm{~m}$, which exhibit highly nonlinear effects and are similar in amplitude with the ISWs observed before the typhoon (not shown). In contrast, the large amplitude ISWs are not present on 30 July, and the existing ISWs are with small amplitude less than $10 \mathrm{~m}$. In addition, the ISWs are also found to reverse their polarities from waves of depression to waves of elevation under the effect of the typhoon. On 29 July, the ISWs all take the form of depression waves, whereas from 05:00 on 30 July, the observed solitons all behave as elevation waves.

After the passage of Washi, as described previously, the near-inertial internal waves now mainly contribute to the variations of the seasonal thermocline. Figure $3 \mathrm{c}$ indicates that the polarities of the waves from 1 August are then affected indirectly by the tropical storm in the form of the nearinertial internal waves. When the trough of the near-inertial wave passes over the site from 20:00 on 1 August to 05:00 on 2 August, the observed ISWs behave as elevation waves, whereas as the shoulder of the near-inertial wave passes at approximately 18:00 on 2 August, the solitons are mainly in the form of depression waves. Particularly, the amplitude of both the elevation and depression ISWs during this period is around $15 \mathrm{~m}$, which is much less than the amplitude of those observed before the typhoon, but a little larger than the solitons observed on 30 July when the water column experiences the strongest effect of the typhoon. Moreover, the ISW packets observed from 30 July to 2 August occurred at the interval of roughly diurnal tidal period, implying that they were likely of the tidal origin.

\section{Discussion}

Our mooring site is located on the continental shelf of the SCS, and the regions next to the site are all with gently varying topography features. The absence of sharply varying topography around our mooring site suggests that the ISWs observed are probably not generated locally by the nonlinear steepening of the near-inertial waves as suggested by Nam et al. (2007). Further, the ISW packets have been observed to occur at the tidal interval, but not with the near-inertial period, which again excludes the possibility of the generation of the ISWs by the near-inertial waves induced by the typhoon wind during our experiment. Instead, the regular arrival of the ISW packets at roughly the diurnal tidal period suggests that the main source of the waves is the tide.

While the tropical storm is not suggested to affect the generation of ISWs on the SCS shelf, it certainly plays key roles in affecting the features of the propagating ISWs as we have described in the previous section. In summary, the main responses of the ISWs to the typhoon include the polarity reversal and amplitude variations of the waves. In this section, we use a two-layer Korteweg-de Vries (KdV) model to give a preliminary theoretical analysis (Liu et al., 1998; Cai et al., 2002; Chen et al., 2007). The nonlinear coefficient $\alpha$ and the linear phase speed $C_{0}$ of the $\mathrm{KdV}$ theory are calculated as below.

$\alpha=\frac{3}{2} \frac{H_{1}-H_{2}}{H_{1} H_{2}} C_{0}$

$C_{0}=\left[\frac{\Delta \rho g H_{1} H_{2}}{\rho\left(H_{1}+H_{2}\right)}\right]^{\frac{1}{2}}$ 

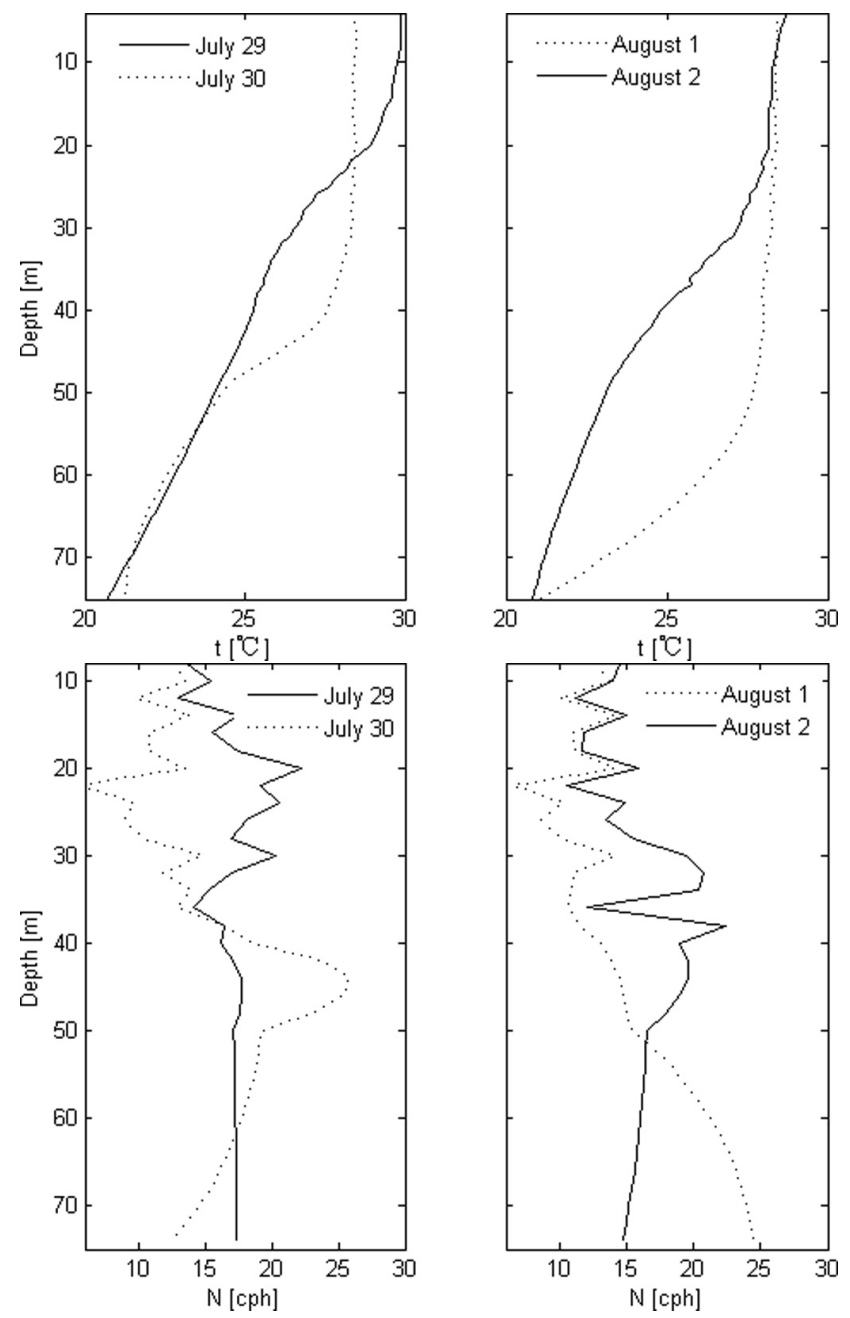

Fig. 4. Temperature and Brunt-Vaisala frequency profiles averaged over the $30 \mathrm{~min}$ before the arrival of the main ISW of the wave packets in different days based on the observed temerature data and the GDEM salinity data.

where $H_{1}$ and $H_{2}$ are the upper layer thickness and lower layer thickness, respectively. $\Delta \rho=\rho_{2}-\rho_{1}$, here $\rho_{1}, \rho_{2}$ is the mean density of the upper layer and lower layer, respectively.

The polarities of the ISWs show a varying pattern during the observational period. According to the two-layer internal wave theory, the waves are of the depression type when the upper layer thickness is smaller than that of the lower layer $\left(H_{1}<H_{2}\right)$, and the waves will transform into the elevation type when the upper layer becomes thicker than the lower layer $\left(H_{1}>H_{2}\right)$.

Before the eye of Washi passed by the mooring site (29 July), the mixed layer depth was around $30 \mathrm{~m}$, while the lower-layer thickness was about $90 \mathrm{~m}$. According to the $\mathrm{KdV}$ theory, the ISWs are expected to be the depression type, which are consistent with the observations (Fig. 4). In contrast, when the tropical storm was in closest distance of the mooring position on $30 \mathrm{July}$, the thermocline was deepened
Table 1. Comparison of the nonlinear coefficients and polarities for the ISWs observed in different days.

\begin{tabular}{lccl}
\hline Date & $\begin{array}{c}\text { Nonlinear } \\
\text { coefficient } \alpha\end{array}$ & $\begin{array}{c}\text { Absolute value } \\
\text { of } \alpha\end{array}$ & Polarity \\
\hline 29 July & -0.04 & 0.04 & Depression \\
30 July & 0.002 & 0.002 & Elevation \\
1 August & 0.013 & 0.013 & Elevation \\
2 August & -0.022 & 0.022 & Depression \\
\hline
\end{tabular}

to $55 \mathrm{~m}$ or deeper owning to the strong vertical mixing induced by the typhoon wind as well as by the depression of the low-frequency internal waves. Thus the ISWs in this period behave as elevation waves.

In addition, as described above, the near-inertial motions begin to dominate the internal wave field after the passage of Washi, though diurnal internal tides are still present. As a result, during the passage of the troughs of the near-inertial internal waves, the mixed layer was at $60 \mathrm{~m}$ depth or deeper, while at the shoulder or peak, the mixed layer was elevated to the $40 \mathrm{~m}$ depth (Fig. 4). Accordingly, on 1 August when $H_{1}>H_{2}$, elevation wave packets occurred, while on $2 \mathrm{Au}-$ gust when the waves appeared during the shoulder of the near-inertial internal wave $\left(H_{1}<H_{2}\right)$, the ISWs were in the form of depression polarity, consistent with the analysis of the internal wave theory (Table 1).

With respect to the varying amplitudes of the ISWs, we caculate the environment conditions for our observational cases (Table 1) and find that the absolute values of nonlinear coefficient $\alpha$, which are sensitive to the stratification structure of the water column, are obviously in close relation with the amplitude variations of the ISWs. For example, the ISWs are largest in amplitude of $40 \mathrm{~m}$ on 29 July when the nonlinear coeffcient reaches the maximum during this period. As the nonlinear coeffcients decrease on 1 August and on 2 August, the solitons also become weaker with the amplitude of roughly $15 \mathrm{~m}$. When the nonlinear coeffcient reaches the minimum and approaches zero on 30 July, the solitons observed are also with the smallest amplitude less than $10 \mathrm{~m}$. These results are consistent with the analysis of the ISWs in the northeastern SCS (Yang et al., 2009).

Particularly, we observed that the strong ISWs with the amplitude of roughly $40 \mathrm{~m}$ on 29 July suddenly disappeared on $30 \mathrm{July}$, which was probably related to the strong mixing caused by the tropical storm. We calculate the gradient Richardson number $R i$ as following:

$R i=N^{2} / S_{\mathrm{v}}^{2}$

where $N$ is the Brunt-Vaisala frequency and $S_{\mathrm{v}}$ is the vertical shear of horizontal currents computed as

$S_{\mathrm{v}}=\sqrt{\left(\frac{\partial u}{\partial z}\right)^{2}+\left(\frac{\partial v}{\partial z}\right)^{2}}$ 
where $u$ is the east velocity component and $v$ is the north velocity component.

Figure 2 shows that on 30 July the upper-layer currents increased up to a maximum of $0.4 \mathrm{~m} \mathrm{~s}^{-1}$, and the vertical shear of the horizontal currents reach a maximum during this period, whereas at the same time the Brunt-Vaisala frequency in the upper layer became much less than that on 29 July (Fig. 4). Therefore the Richardson number in the upper mixed layer on 30 July is significantly reduced to less than a threshold number of $1 / 4$ on 30 July (not shown). Under these conditions, the shear instability will occur and the large amplitude ISWs might break or dissipate, and only small amplitude ISWs can survive, as observed on 30 July (Fructus et al., 2009).

In addition, it should be noted that the Brunt-Vaisala frequency were large around the range of $40-60 \mathrm{~m}$ on 30 July. The Brunt-Vaisala frequency values are also high at the depth around $35-50 \mathrm{~m}$ on 2 August, and at the depth deeper than $55 \mathrm{~m}$ on 1 August, implying the possible existence of deeper thermocline and high Richardson number. However, only the shallower upper mixed layer is essential for the occurrence of the large ISWs, whereas a deeper mixed layer will suppress the generation and propagation of strong ISWs (Shaw et al., 2009).

\section{Conclusions}

The tropical storm Washi is found to lead to significant response of the ISWs in the SCS. The tropical storm does not affect the generation of ISWs originating from the tidetopography interaction in this area, but significantly impact the features of the propagating ISWs. During the arrival of Washi, the ISWs are found to reverse their polarities from waves of depression to waves of elevation. After the passage of Washi, the polarities of the solitons are affected indirectly by the typhoon in the form of the near-inertial internal waves. When the trough of the near-inertial wave passes the site, the ISWs behave as elevation waves, whereas as the shoulder or peak of the near-inertial internal wave occurs, the ISWs are mainly in the form of depression waves.

A theoretical analysis along with the observational results suggest that the absolute values of nonlinear coefficient $\alpha$, which are sensitive to the stratification structure of the water column, are in close relation with the amplitude variations of the ISWs. The largest absolute value of the nonlinear coefficient $\alpha$ coincides with the ocurrence of largest amplitude ISWs on 29 July, while the smallest absolute value of $\alpha$ corresponds to the weakest ISWs on 30 July. The disappearance of the large amplitude ISWs after 29 July are probably due to the decreasing Brunt-Vaisala frequency and increasing baroclinic currents. Under these conditions when the Richardson number is less than $1 / 4$ the shear instability will occur and the large amplitude ISWs might break or dissipate, which will contribute significantly to the local ocean mixing.
This study mainly focuse on the variations of the features of the ISWs under the effects of a tropic storm. The typhoons can enable unexpected transformation of the large amplitude ISWs, which might casue more serious hazards in the ocean interior. Further measurements and dynamical analysis are needed to investigate the detailed impacts on the generation mechanisms and propagation characteristics of the ISWs by the hurricanes or typhoons in the future.

Acknowledgements. This work is supported by Key program of Knowledge Innovation Project of Chinese Academy of Sciences (No. KZCX1-YW-12), National Natural Science Foundation of China (No. 41106017 and No. 41030855), Natural Science Foundation of Jiangsu Province of China (No. BK2011396) and the National 863 program (No. 2008AA09A401).

Topical Editor P. M. Ruti thanks one anonymous referee for her/his help in evaluating this paper.

\section{References}

Bogucki, D. J., Redekopp, L. G., and Barth, J.: Internal solitary waves in the Coastal Mixing and Optics 1996 experiment: Multimodal structure and resuspension, J. Geophys. Res., 110, C02024, doi:10.1029/2003JC002253, 2005.

Cai, S. Q., Long, X. M., and Gan, Z. J.: A numerical study of the generation and propagation of internal solitary waves in the Luzon Strait, Oceanologica Acta, 25, 51-60, 2002.

Chen, C. Y., Hsu, J. R. C., Cheng, M. H., Chen, H. H., and Kuo, C. F.: An investigation on internal solitary waves in a two-layer fluid: Propagation and reflection from steep slopes, Ocean Engineering, 34, 171-184, 2007.

Chu, P., Veneziano, J., Fan, C., Carron, M., and Liu, W.: Response of the South China Sea to Tropical Cyclone Ernie 1996, J. Geophys. Res., 105, 13991-14009, 2000.

Du, T., Tseng, Y. H., and Yan, X. H.: Impacts of tidal currents and Kuroshio intrusion on the generation of nonlinear internal waves in Luzon Strait, J. Geophys. Res., 113, C08015, doi:10.1029/2007JC004294, 2008.

Fructus, D., Carr, M., Grue, J., Jensen, A., and Davies, P. A.: Shear induced breaking of large amplitude internal solitary waves, J. Fluid Mechanics, 620, 1-29, 2009.

Klymak, J. M., Pinkel, R., Liu, C.-T., Liu, A. K., and David, L.: Prototypical solitons in the South China Sea, Geophys. Res. Lett., 33, L11607, doi:10.1029/2006GL025932, 2006.

Lien, R. C., Tang, T. Y., Chang, M. H., and D’Asaro, E. A.: Energy of nonlinear internal waves in the South China Sea, Geophys. Res. Lett., 32, L05615, doi:10.1029/2004GL022012, 2005.

Liu, A. K. and Hsu, M. K.: Internal wave study in the South China Sea using synthetic aperture radar (SAR), Int. J. Remote Sens., 25, 1261-1264, 2004.

Liu, A. K., Chang, Y. S., Hsu, M. K., and Liang, N. K.: Evolution of nonlinear internal waves in the East and South China Seas, J Geophys Res., 103, 7995-8008, 1998.

Liu, P. C., Chen, H. S., Doong, D.-J., Kao, C. C., and Hsu, Y.-J. G.: Monstrous ocean waves during typhoon Krosa, Ann. Geophys., 26, 1327-1329, doi:10.5194/angeo-26-1327-2008, 2008.

Mihanović, H., Orlić, M., and Pasarić, Z.: Diurnal internal tides detected in the Adriatic, Ann. Geophys., 24, 2773-2780, doi:10.5194/angeo-24-2773-2006, 2006. 
Nam, S., Kim, D., Kim, H. R., and Kim, Y.-G.: Typhooninduced, highly nonlinear internal solitary waves off the east coast of Korea, Geophys. Res. Lett., 34, L01607, doi:10.1029/2006GL028187, 2007.

Ramp, S. R., Tang, T. Y., Duda, T. F., Lynch, J. F., Liu, A. K., Chiu, C. S., Bahr, F. L., Kim, H. R., and Yang, Y. J.: Internal solitons in the northeastern South China Sea, Part I: Sources and deep water propagation, IEEE J. Oceanic Eng., 29, 1157-1181, 2004.

Shaw, P.-T., Ko, D., and Chao, S.-Y.: Internal solitary waves induced by flow over a ridge: with applications to the northern South China Sea, J. Geophys. Res., 114, C02019, doi:10.1029/2008JC005007, 2009.

Vlasenko, V. I. and Hutter, K.: Transformation and disintegration of strongly nonlinear internal waves by topography in stratified lakes, Ann. Geophys., 20, 2087-2103, doi:10.5194/angeo-202087-2002, 2002.

Xu, Z. H., Yin, B. S., and Hou, Y. J.: Highly nonlinear internal solitary waves over continental shelf of northwestern South China Sea, Chin, J. Oceanol. Limonol, 28, 1049-1054, 2010a.

Xu, Z. H., Yin, B. S., Hou, Y. J., Fan, Z. S., and Liu, A. K.: A study of internal solitary waves observed on the continental shelf in the northwestern South China Sea, Acta Oceanologica Sinica, $29,18-25,2010 b$.
Xu, Z. H., Yin, B. S., and Hou, Y. J.: Multimodal structure of the internal tides on the continental shelf of the northwestern South China Sea, Estuarine, Coastal and Shelf Science, 95, 178-185, 2011.

Yang, Y. J., Fang, Y. C., Chang, M. H., Ramp, S. R., Kao, C.-C., and Tang, T. Y.: Observations of second baroclinic mode internal solitary waves on the continental slope of the northern South China Sea, J. Geophys. Res., 114, C10003, doi:10.1029/2009JC005318, 2009.

Yuan, Y., Zheng, Q., Dai, D., Hu, X., Qiao, F., and Meng, J.: Mechanism of internal waves in the Luzon Strait, J. Geophys. Res., 111, C11S17, doi:10.1029/2005JC003198, 2006.

Zheng, Q., Susanto, R. D., Ho, C.-R., Song, Y. T., and Xu, Q.: Statistical and dynamical analyses of generation mechanisms of solitary internal waves in the northern South China Sea, J. Geophys. Res., 112, C03021, doi:10.1029/2006JC003551, 2007. 